\title{
Use of intermittent stretch in the prevention of serial sarcomere loss in immobilised muscle
}

\author{
P E Williams
}

\begin{abstract}
After immobilisation of muscle in a shortened position there is a reduction of muscle fibre length due to a loss of serial sarcomeres. Experiments have been carried out to determine whether short, daily periods of stretch prevent sarcomere loss and the resultant loss of range of joint motion. It was found that periods of stretch as short as $1 / 2$ h daily were sufficient not only to prevent loss of sarcomeres but actually to cause an increase in the number of sarcomeres in series. Range of joint motion was normal. Such short periods of stretch were also found to prevent much of the muscle atrophy normally associated with immobilisation in the shortened position.
\end{abstract}

When muscle is immobilised in a shortened position there is both a reduction in muscle fibre length due to a loss of serial sarcomeres ${ }^{12}$ and a remodelling of the intramuscular connective tissue, leading to increased muscle stiffness. ${ }^{34}$ Such changes are likely to produce many of the muscle contractures seen by clinicians, who find that such muscles cannot be passively extended to the full length, which normal joint motion should allow, without the production of muscle pain or injury.

Animal studies have shown that immobilisation of the ankle extensor muscles in a shortened position results in a large reduction of range of joint motion due partly to changes in the joint itself but largely to reduced fibre length and connective tissue changes in the muscles. ${ }^{5}$ It has been shown that very short periods of passive stretch (15 minutes every second day) are sufficient to prevent the connective tissue remodelling. With this regimen sarcomere number is still reduced, with resulting loss of dorsiflexion. ${ }^{5}$

Loss of serial sarcomeres when a muscle is held in a shortened position is considered to be an adaptation to a change in the functional length of the muscle. ${ }^{6}$ In a fully shortened position very little active tension can be developed: loss of sarcomeres results in the remaining sarcomeres being pulled out to a length which enables the muscle to develop its maximum tension in the immobilised position. This results in the length/tension curves of these muscles being shifted to the left of those of controls. Similarly, in muscles immobilised in the lengthened position sarcomeres are added on and this results in sarcomere length being reduced as compared with control muscles. Maximum tension is again found to be developed in the immobilised position and the length/ tension curve is shifted to the right. ${ }^{6}$ Such changes associated with length occur not only in immobilised muscle but also whenever the working length of the muscle is experimentally altered $^{7}$ or where there is postural malalignment. ${ }^{8}$ Thus limitation of range of joint movement is a common complication in patients with musculoskeletal and neurological conditions.

The effect of varying periods of intermittent stretch on muscle which is otherwise immobilised in a shortened position is not known. Experiments have therefore been carried out to determine the effect of short daily stretching regimens on range of joint movement and serial sarcomere number in immobilised mouse soleus muscles. In particular it was hoped to determine whether a threshold duration exists for any stretch induced effect to occur.

\section{Materials and methods}

S/Hy mice were used for these experiments, this strain being particularly suitable for immobilisation studies as after initial handling the animals tolerate the plaster casts very well, and it is also possible to repair or replace casts without the use of anaesthetic. Six groups each containing six adult male mice were used, one group being untreated controls. Animals from the other groups were anaesthetised with a threshold dose of pentobarbital sodium and the right hind leg immobilised by a Plaster of Paris bandage, which held the ankle in the plantar flexed position-that is, with the soleus muscle held in the shortened position. In one group the ankle was immobilised throughout the two week experiment. In the other groups the casts were removed daily and the foot held in dorsiflexion-that is, with the soleus muscle stretched, by a piece of adhesive tape, for periods of $1 / 4 h, 1 / 2 h, 1 \mathrm{~h}$ or $2 \mathrm{~h}$ daily. After the period of stretch the casts were then reapplied, again with the foot in extension. After a two week period of immobilisation or immobilisation combined with intermittent stretch the animals were killed and the range of movement of the ankle measured with a goniometer. The soleus muscles were then removed and weighed before being stretched out on pieces of cork and fixed in $2.5 \%$ glutaraldehyde. After fixation the muscles were placed in $30 \%$ nitric acid for two days, then stored in glycerol. ${ }^{9}$ Single fibres were teased out and mounted in glycerol jelly. A projection microscope was used to count the number of sarcomeres along the length of each fibre. ${ }^{9}$ Measurements were made on three fibres from each muscle. In the soleus there is very little variation in sarcomere number, either within a muscle or between different muscles from animals of the same age (coefficient of variation $=0.28),{ }^{10}$ thus it is necessary to count
University of Hull, Department of Applied P E Williams

Accepted for publication 5 July 1989 
Effect of short daily periods of stretch on muscle immobilised in the shortened position. Results are given as means (SEM)

\begin{tabular}{|c|c|c|c|}
\hline & $\begin{array}{l}\text { Range of } \\
\text { joint } \\
\text { movement (deg) }\end{array}$ & $\begin{array}{l}\text { Serial } \\
\text { sarcomere } \\
\text { number }\end{array}$ & $\begin{array}{l}\text { Muscle } \\
\text { weight } \\
\text { (g) }\end{array}$ \\
\hline $\begin{array}{l}\text { Control } \\
\text { No stretch }\end{array}$ & $163 \cdot 2(0 \cdot 8)$ & $2175(19 \cdot 5)$ & $6 \cdot 42(0 \cdot 14)$ \\
\hline $\begin{array}{l}\text { (immobilised shortened) } \\
1 / 4 \mathrm{~h} \text { stretch/day } \\
1 / 2 \mathrm{~h} \text { stretch } / \text { day } \\
1 \mathrm{~h} \mathrm{stretch/day} \\
2 \mathrm{~h} \mathrm{stretch} / \text { day }\end{array}$ & $\begin{array}{l}96 \cdot 4(5 \cdot 6)^{r+1} \\
146 \cdot 7(4 \cdot 3)^{x \cdot r} \\
162 \cdot 1(0 \cdot 8) \\
163 \cdot 7(1 \cdot 4) \\
162 \cdot 9(0 \cdot 7)\end{array}$ & $\begin{array}{l}1768(21 \cdot 5) \\
2069(26 \cdot 1) \\
2229(34 \cdot 4) \\
2390(15 \cdot 2) \\
2357(42 \cdot 6)\end{array}$ & $\begin{array}{l}3.34(0.23) \\
5.33(0.26) \\
5.86(0.18) \\
6.53(0.24) \\
6.39(0.31)\end{array}$ \\
\hline
\end{tabular}

Significantly different from control value $(p<0.05)$.

Significantly different from control value $(p<0.01)$.

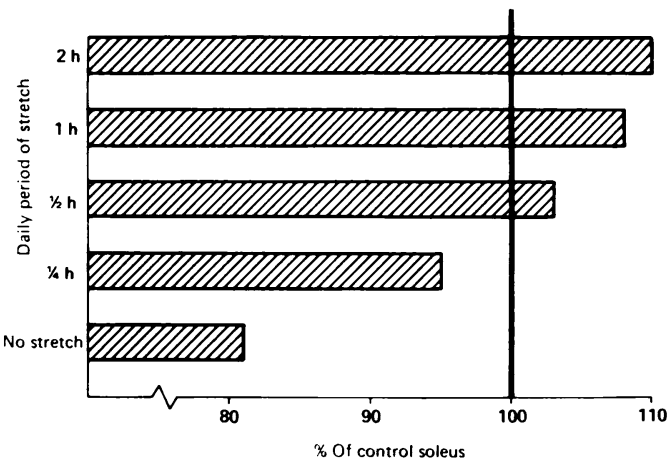

only a small number of fibres from each muscle. Results were compared using a $t$ test.

\section{Results}

After a two week period of immobilisation with the ankle in full plantar flexion there was considerable loss of range of joint motion and the serial sarcomere number in the soleus muscle was reduced by $19 \%$ (table). A regimen of $1 / 4 \mathrm{~h}$ daily stretch throughout the period of immobilisation resulted in improved range of movement and a smaller though still significant reduction in sarcomere number. Periods of stretch lasting $1 / 2 \mathrm{~h}$ or more were found both to maintain normal dorsiflexion of the ankle and to prevent sarcomere loss. Indeed, there was even an increase in serial sarcomere number of as much as $10 \%$ with two hours of daily stretch (figure).

Stretch was also shown to prevent much of the wasting which normally occurs during plaster cast immobilisation. Animals that had received $1 / 2 \mathrm{~h}$ daily stretch showed only $9 \%$ loss in muscle weight compared with a $48 \%$ loss in continuously immobilised muscles (table).

\section{Discussion}

These experiments show that in addition to preventing the remodelling of the intramuscular connective tissue component ${ }^{5}$ daily periods of stretch of $1 / 2 \mathrm{~h}$ or more also prevent the loss of serial sarcomeres which occurs in mouse soleus muscles immobilised in the shortened position. Dorsiflexion of the foot remains normal, thus underlining the importance of muscle fibre length as a factor influencing joint movement.

The experiments also shed some light on the mechanisms involved in the adaptation of sarcomere number. Normal muscle functions at many different lengths, but sarcomere length is optimum at only one. Thus for sarcomere adjustment to occur the muscle fibre must monitor sarcomere length at a particular joint angle or muscle length. In muscle which is continuously immobilised there is obviously only one length which can be monitored-that is, the immobilised length. In muscles which have received intermittent stretch, however, it was not certain whether sarcomere length would adapt to the immobilised muscle length, the stretched length, or an average of the two. With $1 / 2 h$ or more stretch sarcomeres were added on to the fibres, which implies that in these muscles the important position for regulation of sarcomere number is the stretched position. Although the periods of stretch were short, much greater tension would be placed on the muscle attachments in those periods than when the muscle was in the shortened position. This is partly owing to the passive tension that arises when a muscle is stretched to its maximum and also to the active isometric tension developed by the muscle in this position: electromyographic activity of muscles that are immobilised in a stretched position remains almost normal, whereas it rapidly falls in muscles immobilised in the shortened position. ${ }^{11}$ Thus the results support the theory put forward by Herring et al that sarcomere number is regulated so that sarcomere length is optimum for the muscle length at which the highest levels of tension are exerted on the tendon rather than at the habitual or postural joint position. ${ }^{12}$ The fact that adaptation is incomplete in the case of the shortest periods of intermittent stretch may indicate that there is a minimum period of time over which this tension must be maintained for the adaptive process to be started.

The results of the experiments described here also indicate that much of the atrophy associated with immobilisation may be prevented by short periods of stretch. Even $1 / 4 \mathrm{~h}$ a day prevented much of the loss in muscle weight found in continuously immobilised muscle. Work is currently underway to determine whether this is reflected in improved fibre diameter and muscle strength.

This work was supported by a grant from the Arthritis and Rheumatism Council.

1 Tabary J C, Tabary C, Tardieu C, Tardieu G, Goldspink G. Physiological and structural changes in the cat's soleus muscle due to immobilization at different lengths by plaster muscle due to immobilization at different leng

2 Williams P E, Goldspink $G$. The effect of immobilization on the longitudinal growth of striated muscle fibres. $\mathcal{f}$ Anat 1973; 116: 45-55.

3 Goldspink G, Williams P E. The nature of the increased passive resistance in muscle following immobilization of the mouse soleus muscle. 7 Physiol (Lond) 1979; 289: 55.

4 Williams P E, Goldspink G. Connective tissue changes in immobilized muscle. 7 Anat 1984; 138: 343-50.

5 Wiliams P E. Effect of intermittent stretch on immobilized muscle. Ann Rheum Dis 1988; 47: 1014-6.

6 Williams P E, Goldspink $\mathrm{G}$. Changes in sarcomere length and physiological properties in immobilized muscle. $\mathcal{F}$ Anat physiological properti

7 Oudet C L, Petrovic A G. Regulation of the anatomical length of the lateral pterygoid muscle in the growing rat. Advances in P'hysiological Science 1981; 24: 115-21.

8 Kendall H O, Kendall F P, Boynton D A. Posture and pain. Baltimore: Williams and Wilkins, 1952: 103-24

9 Williams P E, Goldspink G. Longitudinal growth of striated muscle fibres. I Cell Sci 1971; 9: 751-67.

10 Williams P E, Goldspink $G$. The effect of denervation and dystrophy on the adaptation of sarcomere number to the functional length of the muscle in young and adult mice. 7 Anat 1976; 122: 455-65.

11 Hnik P, Vejsada R, Goldspink D F, Kasicki S, Kickule I. Quantitative evaluation of electromyogram activity in rat extensor and flexor muscles immobilized at different lengths. Exp Neurol 1985; 88: $515-28$.

12 Herring S W, Grimm A F, Grimm B R. Regulation of sarcomere number in skeletal muscle: a comparison of hypotheses. Muscle Nerve 1984; 7: 161-73. 